\title{
Active-site engineering of $\omega$-transaminase from Ochrobactrum anthropi for preparation of L-2-aminobutyric acid
}

\author{
Zhiwei Zhang ${ }^{\dagger}$, Yang Liư ${ }^{\dagger}$, Jing Zhao, Wenqiang Li, Ruiwen Hu, Xia Li, Aitao Li, Yaping Wang* and Lixin Ma* (D)
}

\begin{abstract}
Background: The unnatural amino acid, L-2-aminobutyric acid (L-ABA) is an essential chiral building block for various pharmaceutical drugs, such as the antiepileptic drug levetiracetam and the antituberculosis drug ethambutol. The present study aims at obtaining variants of $\omega$-transaminase from Ochrobactrum anthropi (OATA) with high catalytic activity to a-ketobutyric acid through protein engineering.

Results: Based on the docking model using a-ketobutyric acid as the ligand, 6 amino acid residues, consisting of Y20, L57, W58, G229, A230 and M419, were chosen for saturation mutagenesis. The results indicated that L57C, M419l, and A230S substitutions demonstrated the highest elevation of enzymatic activity among 114 variants. Subsequently, double substitutions combining $\mathrm{L} 57 \mathrm{C}$ and M419l caused a further increase of the catalytic efficiency to 3.2-fold. This variant was applied for threonine deaminase/OATA coupled reaction in a 50-mL reaction system with $300 \mathrm{mM}$ $\mathrm{L}$-threonine as the substrate. The reaction was finished in $12 \mathrm{~h}$ and the conversion efficiency of L-threonine into L-ABA was $94 \%$. The purity of L-ABA is $75 \%$, >99\% ee. The yield of L-ABA was $1.15 \mathrm{~g}$.
\end{abstract}

Conclusion: This study provides a basis for further engineering of $\omega$-transaminase for producing chiral amines from keto acids substrates.

Keywords: $\omega$-transaminase, Saturation mutagenesis, L-2-aminobutyric acid, Molecular docking, L57C/M419l variant

\section{Background}

L-ABA is an essential chiral building block for various pharmaceutical drugs, such as the antiepileptic drug levetiracetam and the antituberculosis drug ethambutol, etc. [1-3]. The Asymmetric synthesis of L-ABA with both chemocatalytic and biocatalytic strategies has been developed and the biocatalytic methods have attracted growing attention due to environmental and social demands for green processes in the chemical industry

\footnotetext{
*Correspondence: 545080994@qq.com; malixing@hubu.edu.cn †Zhiwei Zhang and Yang Liu have contributed equally to this work State Key Laboratory of Biocatalysis and Enzyme Engineering, Hubei Collaborative Innovation Center for Green Transformation of Bio-Resources, Hubei Key Laboratory of Industrial Biotechnology, College of Life Sciences, Hubei University, 368 Youyi Road, Wuchang, Wuhan 430062, China
}

recently [4]. The most intensively studied biocatalytic methods for the synthesis of L-ABA focus on enzymebased kinetic resolution of ( $R, S)$-2-aminobutyric acid and amination of $\alpha$-ketobutyric acid using L-amino dehydrogenase [5] or transaminase [6]. In the reductive amination process with dehydrogenase using L-threonine as the precursor, formate dehydrogenase $(\mathrm{FDH})$ is added to regenerate $\mathrm{NADH}$. However extra $\mathrm{NAD}^{+}$must be added to the mixture during the reaction in a timely fashion to guarantee the complete bioconversion of L-threonine to L-ABA [7]. Hence, the high cost of $\mathrm{NAD}^{+}$limited its application in the industry.

On the other hand, transaminases are pyridoxal- $5^{\prime}$ phosphate (PLP)-dependent enzymes [8] that are involved in reversible transfer of amino groups from amino donors to carbonyle of amino receptors. 
Transaminases display high reaction rates, broad substrate spectrum, and no requirement of cofactor regeneration [2], which render these enzymes attractive for industrial process development [4, 9]. In 2001, Fotheringham's group developed a three-enzyme system including threonine deaminase, tyrosine aminotransferase, and acetolactate synthase to produce L-ABA with L-aspartic acid and L-threonine as starting materials. L-threonine was converted by threonine deaminase of $E$. coli to obtain $\alpha$-ketobutyric acid, which in turn, converted to L-ABA using the aromatic transaminase of $E$. coli encoded by tyr $\mathrm{B}$, with L-aspartate as the amino donor. Meanwhile, acetolactate synthase from Bacillus subtilis 168 eliminates pyruvate and alanine, which are the by-products of aspartate transamination. The overall yield of $\mathrm{L}-\mathrm{ABA}$ was $54 \%$ [10]. Zhu et al. optimized this method by introducing alanine racemase and D-amino acid oxidase into the system [11]. In 2009, Shin et al. chose a $\omega$-transaminase ( $\omega$-TA) from Vibrio fluvialis JS17 to catalyze the asymmetric synthesis of L-ABA using 2-oxobutyric acid and benzylamine as starting materials in an extractive biphasic reaction system [1]. In 2018, Heuson et al. realized both enantiomers of ABA were efficiently prepared in an equilibrium shifted reaction using glutamine as amine donor [8]. In 2010, Park et al. established a cost-effective $\mathrm{TD} / \omega$-TA coupled one-pot method to produce L-ABA. L-threonine is deaminized with threonine deaminase (TD, EC4.2.1.6) encoded by ilvA gene of $E$. coli to generate $\alpha$-ketobutyric acid in the first step. Next, L-ABA was synthesized through reductive amination with benzylamine as amino donor. (S)-selective $\omega$-TA from Ochrobactrum anthropi (OATA) was employed to catalyze this process. The conversion yield reached $91 \%$ with $10 \mathrm{mM}$ L-threonine and $20 \mathrm{mM}$ benzylamine. Park modified this process by using isopropylamine as amino donor (2013). OATA has exceptionally high activity for isopropylamine and the deamination product of isopropylamine is acetone, a non-reactive amino acceptor easily removable owing to high volatility. Therefore, this reaction overcame the unfavorable equilibrium. Park's study demonstrated a TD/OATA coupled reaction using L-threonine $(100 \mathrm{mM})$ and isopropylamine (2 Equiv.) to generate L-ABA and gained $99 \%$ conversion yield with $99 \%$ ee in $1 \mathrm{~h}$. Preparative scale synthesis with L-threonine $(1.79 \mathrm{~g}$, $15 \mathrm{mmol})$ and isopropylamine $(1.94 \mathrm{~mL}, 22.5 \mathrm{mmol})$ in a 50 -mL reaction system, conversion efficiency of over $99 \%$ was attained within $12 \mathrm{~h} \mathrm{[12].}$

In the TD and OATA cascade reaction, the reaction catalyzed by TD was much faster than that of OATA. Asymmetric synthesis of chiral amines using OATA has suffered from an unfavorable reaction equilibrium when a high concentration of substrate was used [13-15]. Therefore, OATA determines the conversion yield of the whole process. To overcome this limitation, creating OATA variants with high turnover efficiency for asymmetric amination of $\alpha$-ketobutyric acid is necessary [1618]. In the present study, we performed substrate docking simulations to identify key active-site residues around $\alpha$-ketobutyric acid and performed saturation mutagenesis to these amino acid residues. The result indicated that L57C, M419I and A230S substitutions demonstrated the highest elevation of enzymatic activity and double substitutions combining L57C and M419I caused a further increase of the catalytic efficiency. This variant was applied for TD/OATA coupled reaction in a $50-\mathrm{mL}$ reaction system and demonstrated higher conversion efficiency in comparison with wild-type OATA.

\section{Results}

Molecular docking and engineering of OATA

Substrate docking simulation using $\alpha$-ketobutyric acid as the ligand is shown in Fig. 1 (Additional file 2: Table S1). The active site harboring an inward-point arginine (R417) was used for docking simulation [24]. The structure of OATA with pyruvic acid as substrate was used as the template. When R417 adopts an outward conformation, the large pocket becomes too contracted to recognize the carboxyl group. On the contrary, the large pocket is able to accumulate a bigger group, such as keto acid group of $\alpha$-ketobutyric acid

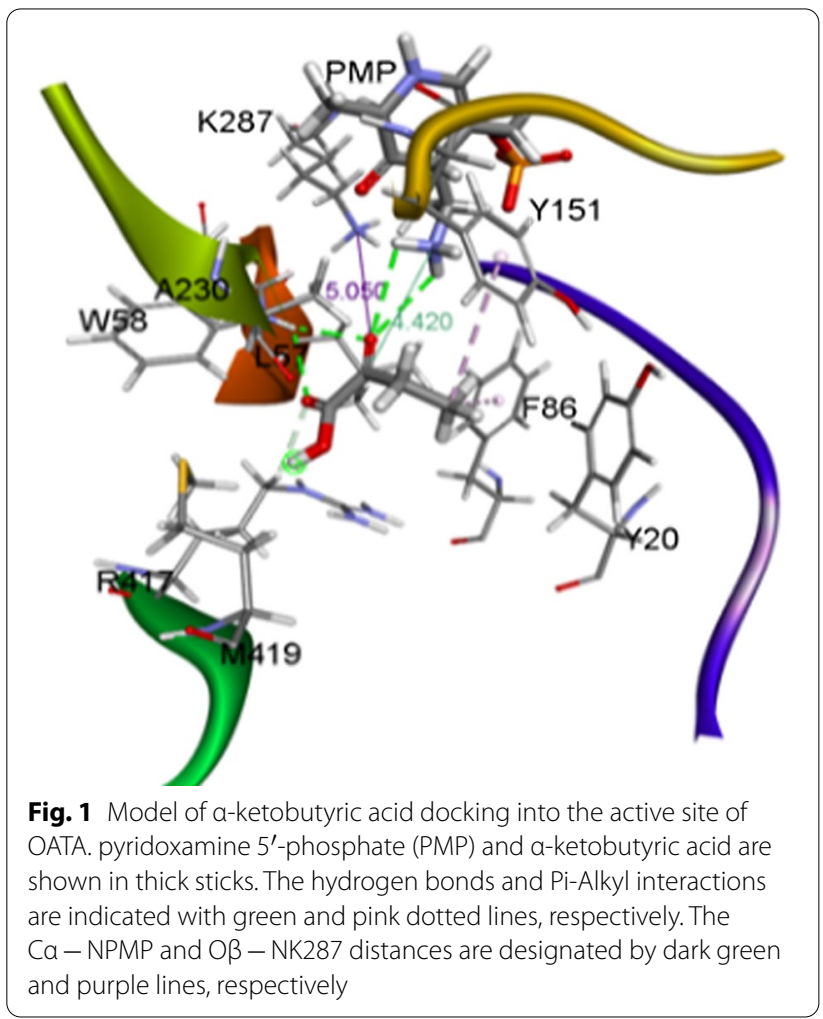


when R417 adopts inward conformation. Therefore, we chose an inward conformation of R417 for docking simulation. For the docking simulation, the ethyl group of $\alpha$-ketobutyric acid is located in a small pocket while the carboxyl group is located in a large pocket. The ethyl group was wrapped by amino acid residues including Y20, F86, Y151, and A230. It is worth noting that W58 and R417 in the large pocket formed multiple hydrogen bonds with the carbonyl oxygen and carboxyl group of the substrate, which implied the importance of those two amino acids.

Based on the result of docking simulation, 6 amino acid residues, consisting of Y20, L57, W58, G229, A230 and M419, lying within a $5 \AA$-distance from the bound $\alpha$-ketobutyric acid were selected for saturation mutagenesis and all the 114 possible variants with a single mutation were generated. The activity of all OATA variants for $\alpha$-ketobutyric acid was tested with thin layer chromatography (TLC). The result of TLC indicated that L57A, L57C, A230S, M419I, M419W, M419C, and M419A displayed an obvious increase in the conversion efficiency of $\alpha$-ketobutyric acid to L-ABA while M419T, and $\mathrm{M} 419 \mathrm{~V}$ showed a slight elevation in comparison with wild-type OATA (Additional file 1: Figure S1). Consistent with the docking model, W58 is an important amino acid residue and all the substitutions of W58 failed to improve the activity of OATA.

Mutants showing obviously improved activity were purified (Additional file 1: Figure S2) and their activities were analyzed with HPLC. The result indicated that three variants L57C, M419I and A230S demonstrated the most obvious improvement, which were 2.7, 1.8 and 1.7-fold, respectively (Fig. 2). To achieve further improvements, these three mutations were combined to generate three double mutants, L57C/A230S, L57C/M419I and A230S/ M419I. Among them, OATA $\mathrm{L}$ 57C/M419I showed the most obvious improvement. Its catalytic efficiency increased 3.2-fold in comparison with wild-type OATA. Both L57C/A230S and A230S/M419I variants demonstrated an elevation of specific activity compared with wild-type, but reduced activity against single mutants (Fig. 2).

\section{Kinetic analysis of L57C/M419I variant}

The kinetic parameters of the wild-type OATA and $\mathrm{OATA}_{\mathrm{L} 57 \mathrm{C} / \mathrm{M} 419 \mathrm{I}}$ was investigated (Table 1, Additional file 1: Figure S5, Additionl file 2: Table S2). The $\mathrm{K}_{\mathrm{m}}$ of the mutant was similar to that of the wild-type enzyme. On the contrary, the catalytic turnover increased 2.2-fold in comparison with the wild-type enzyme, leading to a 2.3fold increase in the $k_{\mathrm{cat}} / \mathrm{K}_{\mathrm{m}}$ for the transaminase. This result indicated that the double mutation affected the catalytic efficiency of OATA.

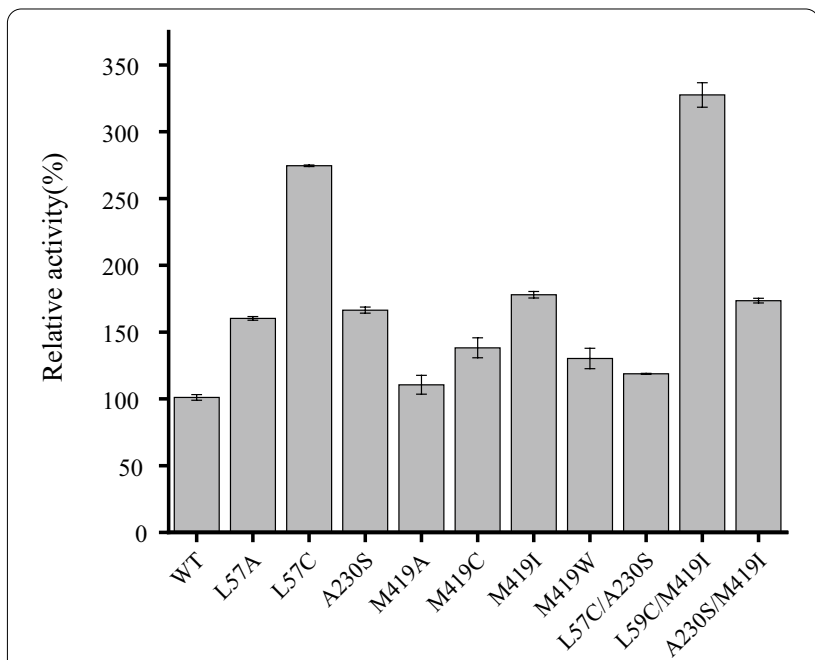

Fig. 2 Comparison of enzyme activities of mutants relative to wild type. The reaction mixture $(100 \mu \mathrm{L})$ contained $0.5 \mathrm{mM}$ PLP, OATA $(0.25 \mathrm{mg} / \mathrm{mL}), 300 \mathrm{mM}$ a-ketobutyric acid, $450 \mathrm{mM}$ isopropylamine and $50 \mathrm{mM}$ phosphate buffer ( $\mathrm{pH}$ 7.5). The reaction was carried out at $37^{\circ} \mathrm{C}$ for $30 \mathrm{~min}$

Table 1 Apparent kinetic parameters of the wild-type OATA and $\mathrm{OATA}_{L 57 C / M 4191}$ for a-ketobutyric acid

\begin{tabular}{lcc}
\hline & Wild-type & L57C/M419| \\
\hline $\mathrm{K}_{\mathrm{m}}(\mathrm{mM})$ & $266 \pm 34$ & $260 \pm 6$ \\
$\mathrm{k}_{\mathrm{cat}}\left(\mathrm{s}^{-1}\right)$ & $5.1 \pm 0.3$ & $11.5 \pm 0.3$ \\
$\mathrm{k}_{\mathrm{cat}} / \mathrm{K}_{\mathrm{m}}\left(\mathrm{M}^{-1} \mathrm{~s}^{-1}\right)$ & $19 \pm 3$ & $44 \pm 1$ \\
\hline
\end{tabular}

The reaction was carried out in a $100-\mu \mathrm{L}$ mixture including $0.5 \mathrm{mM} \mathrm{PLP}$, $0.25 \mathrm{mg} / \mathrm{mL}$ OATA, $50-650 \mathrm{mM}$ a-ketobutyric acid at a fixed concentration of isopropylamine $(1 \mathrm{M})$ and $50 \mathrm{mM}$ phosphate buffer $(\mathrm{pH} 7.5)$. The mixture was incubated at $37^{\circ} \mathrm{C}$ for $30 \mathrm{~min}$

\section{Mechanism analysis for the improved activity of OATA $\mathrm{L57C/}_{\mathrm{L}}$}

M4191

In comparison with the docking location of $\alpha$-ketobutyric acid in the wild-type enzyme, the substrate in the mutant active site spun clockwise and the ethyl group oriented to I419 (Fig. 3A). This translocation allowed a new hydrogen bond formed between the carbonyl oxygen of the substrate and PMP while the preexisting hydrogen bonds between W58 and the substrate were concurrently lost. Meanwhile, hydrophobic interaction formed between I419, A230, and ethyl group of the substrate attributed new forces to stabilize the substrate. The altered binding of $\alpha$-ketobutyric acid in the active site of the mutant led to a significant decrease in the distance between carbonyl carbon of the substrate and the PMP from 4.420 to $3.455 \AA$, which might contribute to the increased catalytic activity.

Molecular dynamics (MD) simulations [19] is powerful in studying the effects of mutations on protein structures 


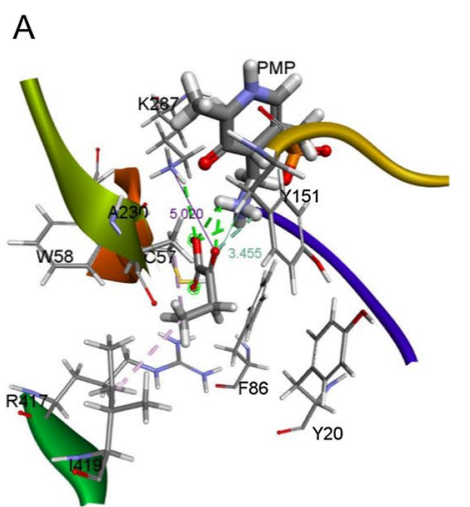

B

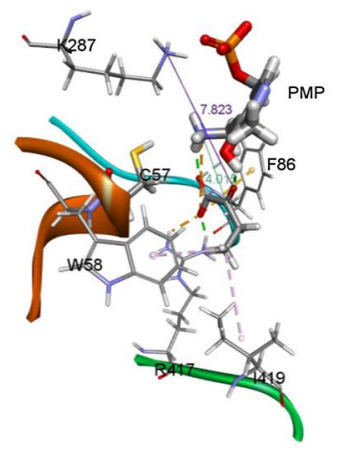

C

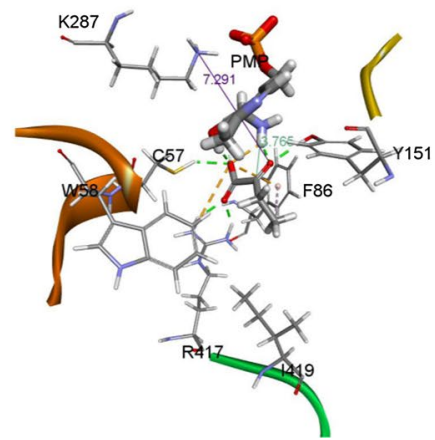

Fig. 3 The mechanism analysis of mutations. A Docking models of the OATA ${ }_{L 57 C / M 4191}$ variant using a-ketobutyric acid as the ligand. B and $\mathbf{C}$ Molecular dynamic simulations of the OATA ${ }_{L 77 C / M 4191}$ variant using a-ketobutyric acid as the ligand. PMP and a-ketobutyric acid are shown in thick sticks. The hydrogen bonds and salt bridge are indicated with green dotted lines and orange dotted lines, and alkyl interactions are labeled with pink dotted lines. The $\mathrm{C}_{\alpha}-\mathrm{N}_{\mathrm{PMP}}$ and $\mathrm{O}_{\beta}-\mathrm{N}_{\mathrm{K} 287}$ distances are designated by dark green and purple lines, respectively

and the impact of protein motions on catalysis [20]. To obtain more details about the interactions between $\alpha$-ketobutyric acid and the amino acid residues in the active site of the L57C/M419I variant, we performed a molecular dynamic simulation using YASARA. Before the molecular dynamic simulation, the docking simulation of $\alpha$-ketobutyric acid in the active site of OATA L57C/M419I was accomplished using YASARA. The conformation of the substrate with the lowest energy was chosen for molecular dynamic simulations (Fig. 3B). The result of molecular dynamic simulation indicated C57 stabilized $\alpha$-ketobutyric acid in the active site and shortened the distance between the carbonyl oxygen of $\alpha$-ketobutyric acid and the amino group of PMP. During the approaching of the substrate to the active site, the hydrophobic interaction between I419 and the substrate was broken, and a hydrogen bond formed between C57 and $\alpha$-ketobutyric acid, resulting in the translocation of carbonyl carbon of the substrate toward PMP (Fig. 3C). The increased accessibility and stability between the substrate and the active site of the variant might lead to an improved $k_{\text {cat }}$.

\section{The stability of the mutants}

The enzyme variants need to retain the intrinsic stability of the wild-type enzyme or gain enhanced stability for their practical applications. Therefore, time-course monitoring of the enzyme activities was performed at $37^{\circ} \mathrm{C}$ for $96 \mathrm{~h}$ in $50 \mathrm{mM}$ phosphate buffer (pH7.5). M419I single mutation improved the stability of OATA (Fig. 4). This variant retained almost all activity after 24 -h incubation at $37{ }^{\circ} \mathrm{C}$ and approximately $80 \%$ of its activity after $96-\mathrm{h}$ treatment. On the other hand, L57C and L57C/M419I variants displayed similar thermostability as wild-type

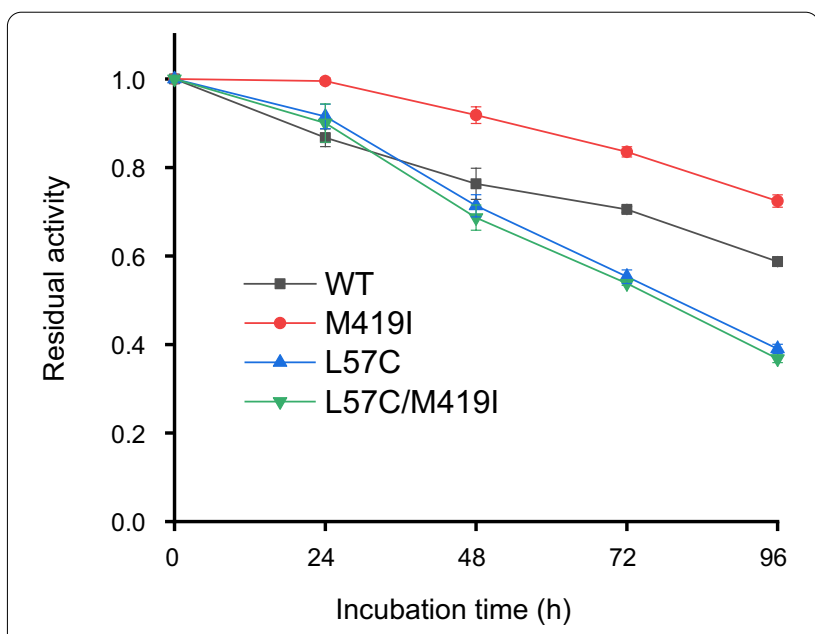

Fig. 4 Effect of mutations on enzyme stability. Purified enzymes were incubated in $50 \mathrm{mM}$ phosphate buffer ( $\mathrm{pH} 7.5)$ with $2.5 \mathrm{mg} /$ $\mathrm{mL}$ OATA at $37^{\circ} \mathrm{C}$. The reaction mixture $(100 \mu \mathrm{L})$ contained $0.5 \mathrm{mM}$ PLP, OATA (0.25 mg/mL), 300 mM a-ketobutyric acid, $450 \mathrm{mM}$ isopropylamine and $50 \mathrm{mM}$ phosphate buffer ( $\mathrm{pH}$ 7.5). The reaction was carried out at $37^{\circ} \mathrm{C}$ for $30 \mathrm{~min}$

OATA in the first $48 \mathrm{~h}$ and became less stable than wildtype with longer treatment (Fig. 4).

\section{Application of OATA L57C/M4191 $_{\text {to }}$ the TD/OATA coupled reaction to generate L-ABA}

OATA $_{\text {L57C/M419I }}$ was utilized for small-scale TD/OATA coupled reaction using L-threonine as the precursor (Fig. 5, Additionl file 2: Table S3). In comparison with wild-type, the conversion efficiency of the double mutant was significantly elevated. The conversion efficiency of L-threonine into L-ABA was $94 \%$ in $12 \mathrm{~h}$. The purity of 


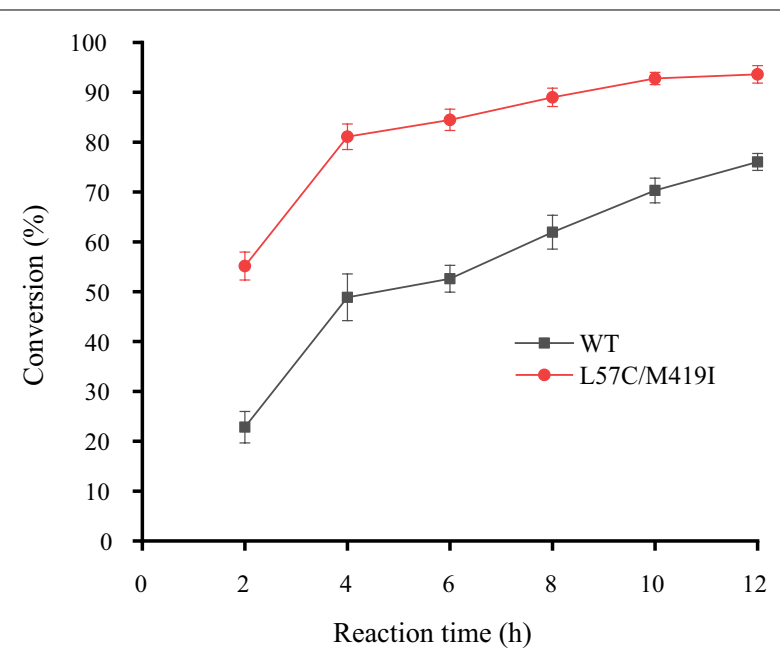

Fig. 5 Small-scale preparation of L-ABA with OATA ${ }_{L 57 C / M 4191}$ and TD. The reaction mixture $(50 \mathrm{~mL})$ contained $0.5 \mathrm{mM} \mathrm{PLP}, \mathrm{TD}(0.2 \mathrm{mg} / \mathrm{mL})$, OATA (1 mg/mL), $300 \mathrm{mM} \mathrm{L}$-threonine, $450 \mathrm{mM}$ isopropylamine and $50 \mathrm{mM}$ phosphate buffer ( $\mathrm{pH} 7.5)$. The reaction was carried out at $37^{\circ} \mathrm{C}$ for $30 \mathrm{~min}$

$\mathrm{L}-\mathrm{ABA}$ was $75 \%,>99 \%$ ee. The yield of $\mathrm{L}-\mathrm{ABA}$ was $1.15 \mathrm{~g}$. However, using wild-type OATA shown in our work only obtained $\sim 74 \%$ completion, while the previous report reached $99 \%$ conversion efficiency [12]. We speculate the acetone or ammonia by product without volatilization could inhibit the activity of OATA.

\section{Discussion}

With the increasing demand for chiral amines, $\omega$ Transaminase has a broader application prospect. However, the natural $\omega$-transaminase still displays drawbacks at stability, and catalytic efficiency. To meet the needs of industrial applications, $\omega$-transaminase and variants with high catalytic activity were obtained through gene mining and protein engineering. The present study is aimed to elevate the catalytic activity of OATA towards $\alpha$-ketobutyric acid through rational design and saturation mutagenesis. $\omega$-transaminase carries two binding pockets, i.e. large and small pockets. The small pocket is found to display a steric constraint prohibiting entry of a substituent larger than an ethyl group, whereas the large pocket can accept a bulk substituent, such as a phenyl group through a hydrophobic interaction [21]. Previous reports indicated L57 is located in the large pocket and exhibits steric interference with the substrate substituent bound in the small pocket $[22,23]$. L57A substitution removed this hindrance and resulted in a mutant with improved specificity towards a large number of bulky substrates [24-26]. In the present study, we found L57C substitution, which has never been reported previously, improved the conversion efficiency of OATA to $\alpha$-ketobutyric acid. Considering L57 is located at the interface the OATA dimer, we proposed that an extra disulfide bond was formed between two monomers due to L57C mutation and increased the stability of the enzyme. The protein bearing L57C substitution was purified as described in the methods section but without the presence of $\beta$-mercaptoethanol. However, MS (mass spectrum) result indicated no novel disulfide bond was formed (data not shown). The result of molecular dynamic simulation indicated C57 formed a novel hydrogen bond with $\alpha$-ketobutyric acid in the active site and shortened the distance between the carbonyl oxygen of $\alpha$-ketobutyric acid and the amino group of PMP, in turn, promoted the transamination. Meanwhile, M419, a residue away from the active site, is also proved to be important to the enzymatic activity of OATA. the structure of OATA (5GHF) indicated M419 is located at the entrance of the active site (Fig. 1). Therefore, M419 interacts with $\alpha$-ketobutyric acid before it enters the active site. This theory may explain why the substitutions of M419 to nonpolar amino acids, such as Ala, Val, and Ile are all able to improve the activity of OATA while all substitution of charged amino acid residues decreases its activity. Among them, M419I showed the most obvious effect. The molecular dynamic simulation demonstrated hydrophobic interaction was formed between Ile and $\alpha$-ketobutyric acid, which facilitated the entrance of the substrate to the active site. Since I419 and C57 interact with $\alpha$-ketobutyric acid individually during the approach of the substrate to PMP, these two substitutions have synergistic effect in improving the activity of OATA.

\section{Conclusion}

In conclusion, the present study is another successful example for the engineering of $\omega$-Transaminase and the result of the present study expands the pool of amino acid residues for future protein engineering of $\omega$-TA. OATA $_{\mathrm{L} 57 \mathrm{C} / \mathrm{M} 419 \mathrm{I}}$ showed the most obvious improvement of catalytic efficiency in comparison with wild-type OATA. In the future, we will apply this mutant to other ketone acids and ketone substrates to broaden its industrial application.

\section{Methods}

Strains, plasmids, medium, and reagents

Escherichia coli $\mathrm{DH} 5 \alpha$ for gene cloning was from TaKaRa (China). The expression vector pET28a and $E$. coli BL21 (DE3) was from Novagene (Beijing, China). Expression vectors for the heterologous expression of TD and OATA were constructed in the present study. Briefly, the ORF of ilvA from E. coli K12 (GenBank accession number: NP_418220.1) was amplified with F1/R1 (Additional file 1: Table S1) and cloned into pET28a vector 
using the T5 exonuclease mediated cloning method [27]. The ORF encoding OATA (GenBank accession number: WP_011982390.1) was optimized based on the codon usage preference of $E$. coli without changing the amino acid sequence and synthesized by Sangon (China). The ORF was also cloned into the pET28a vector using the T5 exonuclease mediated cloning method. To facilitate the purification, the recombinant TD and OATA were expressed with a $6 \times$ His tag fused to their C-termini. The recombinant plasmids were identified with DNA sequencing and named pET28a-TD-His6 and pET28aOATA-His6, respectively.

Luria-Bertani (LB) medium for the cultivation of $E$. coli was prepared as described in the Manual of Molecular Cloning [28]. L-threonine, $\alpha$ - ketobutyric acid, and isopropylamine were purchased from Aladdin (China). All other chemicals were analytical reagents.

\section{Expression and purification of recombinant TD and OATA}

To induce the expression of the target gene, the transformants were incubated at $37{ }^{\circ} \mathrm{C}$ to $\mathrm{OD}_{600}$ of $0.6-0.8$ and then induced with $1 \mathrm{mM}$ of IPTG at $18{ }^{\circ} \mathrm{C}$ for $24 \mathrm{~h}$. Cells were collected and resuspended in lysis buffer $(50 \mathrm{mM}$ Tris-HCl; $50 \mathrm{mM} \mathrm{NaCl} ; 1 \mathrm{mM} \quad \beta$-mercaptoethanol; $0.1 \mathrm{mM}$ PMSF; $0.5 \mathrm{mM}$ PLP; pH7.0). The samples were ultrasonicated to break the cells. The crude cell lysate was collected after centrifugation at $12,000 \times \mathrm{g}$ for $30 \mathrm{~min}$. The supernatant was applied to Ni-NTA beads for affinity purification. The column was washed twice with $10 \mathrm{col}-$ umn volume of wash buffer $(50 \mathrm{mM}$ Tris- $\mathrm{HCl} ; 50 \mathrm{mM}$ $\mathrm{NaCl}$; 0.5 mM PLP; 20 mM Imidazole, pH7.0). Ten column volume of elution buffer $\left(20 \mathrm{mM} \mathrm{Na} \mathrm{PO}_{4}, 0.5 \mathrm{M} \mathrm{NaCl}\right.$; $0.5 \mathrm{mM}$ PLP; $200 \mathrm{mM}$ Imidazole, pH7.0) was used to recover the target protein. The sample was then collected and dialyzed with a Millipore 30-kDa cut-off membrane at $4{ }^{\circ} \mathrm{C}$ to remove imidazole and salts, followed by resuspending with storage buffer $\left(50 \mathrm{mM} \mathrm{Na} \mathrm{PO}_{4}, 0.15 \mathrm{M} \mathrm{NaCl}\right.$; $0.5 \mathrm{mM}$ PLP; $\mathrm{pH} 7.0$ ). The protein concentration was determined by Bradford Protein Assay Kit (Beyotime).

\section{The determination of protein concentration by Bradford Assay kit}

Dilute BSA gradient with storage buffer of OATA to make the final concentration of BSA $0.125,0.25,0.5,0.75,1 \mathrm{mg} /$ $\mathrm{mL}$ and $1.5 \mathrm{mg} / \mathrm{mL}$, respectively. Take diluted samples $(5 \mu \mathrm{L})$ to 96 well plates, followed by adding $250 \mu \mathrm{L}$ G250 staining solution in triplicates for each sample, and then determine the absorbance at $\mathrm{OD}_{595}$ with a microplate reader. Take the absorbance value as the vertical axis and the BSA standard protein concentration as the horizontal axis, fit the BSA linear standard curve, calculate the linear regression equation, and then calculate the protein concentration of OATA according to the standard equation.

\section{Molecular modeling and selecting of mutation sites}

The crystal structure of OATA (PDB ID: 5GHF) was used for the molecular simulation. The 1-31 amino acids of chain A in OATA was constructed using the Modeler module (version 9.8) with chain B as the template. Docking simulation was performed with the Discovery Studio (version 20.1.0). Docking simulation with $\alpha$-ketobutyric acid as the ligand was accomplished using the Flexible Docking (the active site defined by the Binding-Site module, under a default setting of 2000 steps at $700 \mathrm{~K}$ for a heating step; 5000 steps at $300 \mathrm{~K}$ for a cooling step; $8 \AA$ grid extension). The docking locates most similar to the previous report using pyruvic acid [29] as a ligand was chosen as the docking model.

The active-site models of the L57C/M419I variants were built by amino acid substitution and energy minimization (2000 steps; dielectric constant 4) of the mutation sites.

\section{Site-directed mutagenesis}

To generate each OATA variant, a pair of oligonucleotides including the substitutions (Additional file 1: Table S1) were synthesized and used for reverse PCR with pET28a-OATA as a template (Additional file 2: Figure S1). The PCR product was digested with $D p n \mathrm{I}$, followed by transformation of $E$. coli DH5 $\alpha$. The mutations were identified with DNA sequencing (Sangon, China).

\section{Analysis of the enzymatic activity of OATA}

The enzyme activity was measured with $\alpha$-ketobutyric acid and isopropylamine as substrates. Briefly, $10 \mu \mathrm{L}$ of enzyme sample $(2.5 \mathrm{mg} / \mathrm{mL})$ was added to $90 \mu \mathrm{L}$ of reaction mixture containing $300 \mathrm{mM} \alpha$-ketobutyric acid and $450 \mathrm{mM}$ isopropylamine in $50 \mathrm{mM}$ phosphate buffer (pH7.5), followed by incubating at $37^{\circ} \mathrm{C}$ for $30 \mathrm{~min}$. The reaction was terminated with $100 \mu \mathrm{L}$ of acetonitrile and the sample was centrifuged at $14,000 \times \mathrm{g}$ for $10 \mathrm{~min}$. The supernatant was diluted 5 times with $400 \mu \mathrm{L}$ of deionized $\mathrm{H}_{2} \mathrm{O}$, followed by analysis with HPLC. All experiments were done in triplicate.

\section{Molecular dynamics simulations of OATAL57C/M419I}

The model structure of OATAL57C/M419I was used for molecular dynamics simulations. Molecular dynamics simulations were performed with the YASARA(v18.4.24). Introducing $\alpha$-ketobutyric acid as a ligand into the receptor was similar to the docking simulation (the active site defined by the Binding-Site module, under a default setting of pH7.5 for the environmental pH.; $8 \AA$ grid extension; energy minimization with the protein).

\section{Kinetic analysis}

To obtain kinetic parameters for $\alpha$-ketobutyric acid, a pseudo-one-substrate kinetic model was used as described previously [25]. The kinetic parameters were determined 
from three independent initial rate measurements performed with the same batch of purified enzymes. The concentration of $\alpha$-ketobutyric acid was 50 to $650 \mathrm{mM}$ while the concentration of isopropylamine was fixed to $1 \mathrm{M}$. The initial rate was measured by HPLC analysis of produced L-ABA. Initial rate data were fitted to a Michaelis-Menten equation, and the $\mathrm{K}_{\mathrm{m}}$ and $k_{\text {cat }}$ values were calculated from the slope and $y$-intercept of the double-reciprocal plot.

\section{Screening of OATA mutants with high activity}

To prepare the $\alpha$-ketobutyric acid substrate for the enzyme assay of OATA variants, E. coli BL21 (DE3) strain bearing pET28a-TD-His6 was incubated in $200 \mathrm{~mL}$ of LB media at $37{ }^{\circ} \mathrm{C}$ until $\mathrm{OD}_{600}$ reached $0.6-0.8$, followed by inducing with $1 \mathrm{mM}$ of IPTG at $18^{\circ} \mathrm{C}$ for $12-16 \mathrm{~h}$. The cells were collected and added to $200 \mathrm{~mL}$ of reaction mixture containing $300 \mathrm{mM}$ L-threonine and $450 \mathrm{mM}$ isopropylamine in $50 \mathrm{mM}$ of phosphate buffer (pH7.5). The reaction was carried out at $37{ }^{\circ} \mathrm{C}$ for $2 \mathrm{~h}$. Thin-layer chromatography (TLC) with Silica TLC gel $60 \mathrm{~F}_{10-20 \mathrm{~cm}}$ from Haiyang Chemical Co., Ltd. (Qingdao, China) was performed to monitor the progress of the reaction. After L-threonine was conversed to $\alpha$-ketobutyric acid, the supernatant was collected by centrifugation at $10,000 \times \mathrm{g}$ for $10 \mathrm{~min}$. E. coli BL21 (DE3) strains bearing various pET28a-OATA-His6 variants were incubated in $8 \mathrm{~mL}$ of $\mathrm{LB}$ media at $37^{\circ} \mathrm{C}$ until $\mathrm{OD}_{600}$ reached $0.6-0.8$, followed by inducing with $1 \mathrm{mM}$ of IPTG at $18{ }^{\circ} \mathrm{C}$ for $14 \mathrm{~h}$. The cells were collected and added to $1 \mathrm{~mL}$ of $\alpha$-ketobutyric acid prepared as above mentioned. The reaction was carried out at $37^{\circ} \mathrm{C}$ for $1 \mathrm{~h}$, followed by detection with thin-layer chromatography using Silica TLC gel $60 \mathrm{~F}_{10-20 \mathrm{~cm}}$. The solvent system contained A solution and B solution in a ratio of $4: 3(\mathrm{v} / \mathrm{v})$. A solution was $1 \%(\mathrm{w} / \mathrm{v})$ ninhydrin in $\mathrm{N}$-butanol and $\mathrm{B}$ solution was acetic acid in deionized $\mathrm{H}_{2} \mathrm{O}(1: 2, \mathrm{v} / \mathrm{v})$. After the chromatography, the sildes were dry with a hair drier and the dotes of L-ABA show red color.

\section{HPLC analysis and chiral analysis of L-ABA}

HPLC analysis were performed on a Shimadzu HPLC system (Japan). Analysis of L-ABA and $\alpha$-ketobutyric acid were performed using YMC-Pack Diol-120-NP column with isocratic elution with $80 \%$ Acetonitrile-20\% $\mathrm{NH}_{4} \mathrm{H}_{2} \mathrm{PO}_{4}(10 \mathrm{mM}, \mathrm{pH} 2.0)$ at $1 \mathrm{~mL} / \mathrm{min}$. The column oven temperature was set to $40{ }^{\circ} \mathrm{C}$, UV detection was done at $200 \mathrm{~nm}$ (Additional file 1: Figure S3). To analyze the chirality of L-ABA, L-ABA was derivatized using D-glucopyranosyl isothiocyanate (GITC) $[30,31]$ and detected using a C18 symmetry column (Waters, USA) with $50 \%$ methanol and $50 \%$ water (containing $0.1 \% \mathrm{TFA}$ ) at a speed of $1 \mathrm{~mL} / \mathrm{min}$. The column oven temperature was set to $40{ }^{\circ} \mathrm{C}$. UV detection was done at $254 \mathrm{~nm}$ (Additional file 1: Figure S4).

\section{TD/ $\omega$-TA coupled reactions}

The coupled reaction for the synthesis of L-ABA was performed at $37{ }^{\circ} \mathrm{C}$ with $300 \mathrm{mM} \mathrm{L}$-threonine, $450 \mathrm{mM}$ isopropylamine, $0.5 \mathrm{mM}$ PLP in $50 \mathrm{mM}$ phosphate buffer (pH7.5). The concentrations of TD and OATA were $0.2 \mathrm{mg} / \mathrm{mL}$ and $1 \mathrm{mg} / \mathrm{mL}$, respectively. L-ABA was analyzed for measurements of conversion yield and enantiomeric excess.

\section{Purification of L-2-aminobutyric acid}

At the end of the reaction, the reaction solution was heated at $60^{\circ} \mathrm{C}$ for $30 \mathrm{~min}$ (denature and precipitate the enzymes), followed by centrifuging at $12,000 \mathrm{rpm}$ for $30 \mathrm{~min}$. The supernatant was collected and filtrated by a $0.45-\mu \mathrm{m}$ filter membrane. The filtrate solution was subjected to cation-exchange by Dowex 50WX8 cation-exchange resin $(50 \mathrm{~g})$ in a $50-\mathrm{mL}$ column with rotation for $2 \mathrm{~h}$, followed by washing with $0.1 \mathrm{~N} \mathrm{HCl}(120 \mathrm{~mL})$ and water $(120 \mathrm{~mL})$ sequentially. The product was eluted with $145 \mathrm{~mL}$ of $10 \%$ ammonia solution [12]. The elution was transferred to the rotary evaporator for rotary evaporation at $60-70^{\circ} \mathrm{C}$. After the water was evaporated, the precipitated crystals are washed for three times with ethanol. After each cleaning, $\mathrm{L}-\mathrm{ABA}$ is obtained by suction filtration.

\section{Statistical analysis}

Experiments were performed in triplicates. The statistical analyses were processed in originlab 2019b, and the structural analysis of OATA was carried out by Discovery Studio 2016 and YASARA (v18.4.24).

\section{Abbreviations}

L-ABA: L-2-aminobutyric acid; PLP: Pyridoxal-5' - phosphate; $\omega$-TA: $\omega$-Transaminase; TD: Threonine deaminase; OATA: $\omega$-Transaminase from Ochrobactrum anthropi; TLC: Thin layer chromatography.

\section{Supplementary Information}

The online version contains supplementary material available at https://doi. org/10.1186/s12896-021-00713-7.

Additional file 1. Supplementary materials of the full text, including of Table S1:The design of primers in six different amino acid sites; Figure S1: Thin-layer chromatography (TLC) to evaluate catalytic activities of the mutants for a-ketobutyric acid; Figure S2: SDS-PAGE to analyze the purified mutant protein. Figure S3: The concentration of L-2-Aminobutyric acid was detected by HPLC; Figure S4: Chiral analysis of aminobutyric acid; Figure S5: Enzyme kinetic curve of $\omega$-transaminase.

Additional file 2. Raw materials of the full text, containing the original, unprocessed and uncropped version of the table 1, Fig 2 and Fig 5 in manuscript. The schematic view of the pET28 plasmid as well as the designed gene structure in assay.

\section{Acknowledgements} Not applicable. 


\section{Authors' contributions}

$Z Z, Y L$ designed the work and performed most experiments. JZ, WL, RH, and AL performed the molecular docking and analyzed the experiments results. XL participated in completing part of the study. YW and LM interpreted part of data and wrote the manuscript. All authors read and approved the final manuscript.

\section{Funding}

This work was supported by China National Key Research and Development (R\&D) Program (2021YFC2100100) and a major technological innovation project in Hubei province (2017ACA174).

\section{Availability of data and material}

All data generated or analyzed during this study are included in this published article and its supplementary information/additional files. Sequence data used in this study is deposited in the GenBank under the accession Numbers: WP_011982390.1 (OATA) and WP_000785596.1 (TD).

\section{Declarations}

Ethics approval and consent to participate Not applicable.

\section{Consent to publication}

Not applicable.

\section{Competing interests}

The authors declare that they have no competing interests.

Received: 21 January 2021 Accepted: 6 September 2021

Published online: 25 September 2021

\section{References}

1. Shin JS, Kim BG. Transaminase-catalyzed asymmetric synthesis of L-2-aminobutyric acid from achiral reactants. Biotechnol Lett. 2009;31:1595-9. https://doi.org/10.1007/s10529-009-0057-7.

2. Taylor PP, Pantaleone DP, Senkpeil RF, Fotheringham IG. Novel biosynthetic approaches to the production of unnatural amino acids using transaminases. Trends Biotechnol. 1998;16:412-8. https://doi.org/10. 1016/s0167-7799(98)01240-2.

3. Xu JM, Li JQ, Zhang B, Liu ZQ, Zheng YG. Fermentative production of the unnatural amino acid L-2-aminobutyric acid based on metabolic engineering. Microb Cell Fact. 2019;18:43. https://doi.org/10.1186/ s12934-019-1095-z.

4. Malik MS, Park ES, Shin JS. Features and technical applications of w-transaminases. Appl Microbiol Biotechnol. 2012;94:1163-71. https:// doi.org/10.1007/s00253-012-4103-3.

5. Tao R, Jiang Y, Zhu F, Yang S. A one-pot system for production of L-2-aminobutyric acid from L-threonine by L-threonine deaminase and a NADH-regeneration system based on L-leucine dehydrogenase and formate dehydrogenase. Biotechnol Lett. 2014;36:835-41. https://doi.org/ 10.1007/s10529-013-1424-y.

6. Guo F, Berglund P. Transaminase biocatalysis: optimization and application. Green chem. 2017;19:333-60. https://doi.org/10.1039/C6GC02328B.

7. Wang Y, Li GS, Qiao P, Lin L, Xue HL, Zhu L, Wu MB, Lin JP, Yang LR. Increased productivity of L-2-aminobutyric acid and total turnover number of $\mathrm{NAD}(+) / \mathrm{NADH}$ in a one-pot system through enhanced thermostability of L-threonine deaminase. Biotechnol Lett. 2018;40:1551-9. https://doi.org/10.1007/s10529-018-2607-3.

8. Heuson E, Charmantray F, Petit JL, et al. Enantioselective synthesis of $\mathrm{D}$ - and $\mathrm{L}$-a-amino acids by enzymatic transamination using glutamine as smart amine donor. Adv Synth Catal. 2018. https://doi.org/10.1002/adsc. 201801278.

9. Cheng F, Chen XL, Xiang C, Liu ZQ, Wang YJ, Zheng YG. Fluorescencebased high-throughput screening system for R-omega-transaminase engineering and its substrate scope extension. Appl Microbiol Biotechnol. 2010;104:2999-3009. https://doi.org/10.1007/s00253-020-10444-y.
10. David TL, Ager J, David P, et al. Novel biosynthetic routes to non-proteinogenic amino acids as chiral pharmaceutical intermediates. J Mol Catal B: Enzymatic. 2001;11:199-205.

11. Zhu L, Tao R, Wang Y JY, Lin X, Yang Y, Zheng H, Jiang W, Yang S. Removal of $\mathrm{L}$-alanine from the production of $\mathrm{L}$-2-aminobutyric acid by introduction of alanine racemase and D-amino acid oxidase. Appl Microbiol Biotechnol. 2001;90:903-10. https://doi.org/10.1007/ s00253-011-3127-4.

12. Park ES, Dong JY, Shin JS. $\omega$-Transaminase-catalyzed asymmetric synthesis of unnatural amino acids using isopropylamine as an amino donor. Org Biomol Chem. 2013;11:6929-33. https://doi.org/10.1039/ c3ob40495a.

13. Shin JS, Kim BG. Kinetic modeling of omega-transamination for enzymatic kinetic resolution of alpha-methylbenzylamine. Biotechnol Bioeng. 1998;60:534-40.

14. Shin JS, Kim BG. Substrate inhibition mode of omega-transaminase from Vibrio fluvialis JS17 is dependent on the chirality of substrate. Biotechnol Bioeng. 2002;77:832-7. https://doi.org/10.1002/bit.10165.

15. Taday F, Ryan J, Argent SP, Caprio V, Macia B, O'Reilly E. Asymmetric construction of alkaloids by employing a key omega-transaminase cascade. Chemistry. 2020;26:3729-32. https://doi.org/10.1002/chem.202000067.

16. Gao X, Zhang X, Zhu N, Mou Y, Zhang H, Liu X, Wei P. Reshaping the substrate binding region of (R)-selective omega-transaminase for asymmetric synthesis of (R)-3-amino-1-butanol. Appl Microbiol Biotechnol. 2020;104:3959-69. https://doi.org/10.1007/s00253-020-10539-6.

17. Gavin DP, Reen FJ, Rocha-Martin J, Abreu-Castilla I, Woods DF, Foley AM, Sanchez-Murcia PA, Schwarz M, O'Neill P, Maguire AR, O'Gara F. Genome mining and characterisation of a novel transaminase with remote stereoselectivity. Sci Rep. 2019;9:202. https://doi.org/10.1038/ s41598-019-56612-7.

18. Voss M, Xiang C, Esque J, Nobili A, Menke MJ, Andre I, Hohne M, Bornscheuer UT. Creation of (R)-amine transaminase activity within an alpha-amino acid transaminase scaffold. ACS Chem Biol. 2020;15:416-24. https://doi.org/10.1021/acschembio.9b00888.

19. Liu X, Shi D, Zhou S, Liu H, Liu H, Yao X. Molecular dynamics simulations and novel drug discovery. Expert Opin Drug Discov. 2018;13:23-37. https://doi.org/10.1080/17460441.2018.1403419.

20. Radkiewicz JL, Brooks CL. Protein dynamics in enzymatic catalysis: exploration of dihydrofolate reductase. J Am Chem Soc. 2000;122:225-31.

21. Kwon S, Lee JH, Kim CM, Jang H, Yun H, Jeon JH, So I, Park HH. Structural basis of substrate recognition by a novel thermostable (S)-enantioselective $\omega$-transaminase from Thermomicrobium roseum. Sci Rep. 2019;9:6958. https://doi.org/10.1038/s41598-019-43490-2.

22. Park ES, Kim M, Shin JS. Molecular determinants for substrate selectivity of $\omega$-transaminases. Appl Microbiol Biotechnol. 2012;93:2425-35. https:// doi.org/10.1007/s00253-011-3584-9.

23. Hwang BY, Ko SH, Park HY, Seo JH, Lee BS, Kim BG. Identification of $\omega$-aminotransferase from Caulobacter crescentus and site-directed mutagenesis to broaden substrate specificity. J Microbiol Biotechnol. 2008;18:48-54.

24. Han SW, Park ES, Dong JY, Shin JS. Active-site engineering of $\omega$-transaminase for production of unnatural amino acids carrying a side chain bulkier than an ethyl substituent. Appl Environ Microbiol. 2015;81:6994-7002. https://doi.org/10.1128/aem.01533-15.

25. Han SW, Park ES, Dong JY, Shin J-S. Mechanism-guided engineering of $\omega$-transaminase to accelerate reductive amination of ketones. Adv Synth Catal. 2015;357:1732-40. https://doi.org/10.1002/adsc.201500211.

26. Han SW, Park E-S, Dong JY, Shin JS. Expanding substrate specificity of $\omega$-transaminase by rational remodeling of a large substrate-binding pocket. Adv Synth Catal. 2015;357:2712-20. https://doi.org/10.1002/adsc. 201500239.

27. She W, Ni J, Shui K, Wang F, He R, Xue J, Reetz MT, Li A, Ma L. Rapid and error-free site-directed mutagenesis by a PCR-free in vitro CRISPR/Cas9mediated mutagenic system. ACS Synth Biol. 2018;7:2236-44. https://doi. org/10.1021/acssynbio.8b00245.

28. Sambrook J, Russell D, Maccallum P. Molecular cloning: a laboratory manual. 3rd ed. New York: Cold Spring Harbor Laboratory; 2018.

29. Han SW, Kim J, Cho HS, Shin JS. Active site engineering of $\omega$-transaminase guided by docking orientation analysis and virtual activity screening. ACS Catal. 2017;7:3752-62. 
30. Xie S, Zeng S. Stereoselective glucuronidation of propafenone and its analogues by human recombinant UGT1A9. Chem Pharm Bull (Tokyo). 2010;58:879-83. https://doi.org/10.1248/cpb.58.879.

31. Péter A, Olajos E, Casimir R, Tourwé D, Broxterman QB, Kaptein B, Armstrong DW. High-performance liquid chromatographic separation of the enantiomers of unusual alpha-amino acid analogues. J Chromatogr A. 2000:871:105-13. https://doi.org/10.1016/s0021-9673(99)00889-4.

\section{Publisher's Note}

Springer Nature remains neutral with regard to jurisdictional claims in published maps and institutional affiliations.
Ready to submit your research? Choose BMC and benefit from:

- fast, convenient online submission

- thorough peer review by experienced researchers in your field

- rapid publication on acceptance

- support for research data, including large and complex data types

- gold Open Access which fosters wider collaboration and increased citations

- maximum visibility for your research: over 100M website views per year

At BMC, research is always in progress.

Learn more biomedcentral.com/submissions 